\title{
What's Good What's Bad? Conceptualising Teaching and Learning Methods as Technologies Using Actor Network Theory in The Context of Palestinian Higher Education
}

Karl Royle, University of Wolverhampton, Wolverhampton, UK, K.royle@wlv.ac.uk

If a dancer stops dancing, the show is finished, no inertia will carry us forward. (Latour 2005: 37)

\begin{abstract}
This paper analyses Problem Based Learning (PBL) as part of an Actor Network within the (2016-19) Erasmus Plus project Modernization of Teaching Methodologies in Higher Education: EU experience for Jordan and Palestinian territory (METHODS). This project introduced a range of learning modalities into formal learning contexts in higher education settings in Jordan (4 Universities) and Palestine (4 Universities). The project was jointly led by the University of Jordan and the University of Birzeit, Palestine, and there were six European partner universities. The paper focuses on the positioning of PBL approaches as a socio-intellectual technology within an Actor Network through which the impacts of the project might be analysed. PBL is conceptualised as an actant in a heterogenous network of human and non-human actors that reframes the participants' relationships with each other and the network within which they are located. Equally, through this reframing, the paper considers whether greater realisations of self-organisation and agency are enacted or evidenced within the findings of semi-structured group interviews with students and corresponding staff across a range of undergraduate courses in the arts and sciences within the Palestinian context.
\end{abstract}

Keywords: Problem based learning, Human agency, Actor Network Theory, Technology, Teaching and Learning methods, Erasmus Plus

\section{Introduction}

This paper retrospectively reviews the outcomes of the introduction of Problem Based Learning (PBL) within four Palestinian universities across 21 courses, ranging from teacher education to computer engineering. It conceptualises PBL as a socio-intellectual technology and as a non-human actor within a network of other actors within higher education. Definitions of teaching and learning as a socio-intellectual technology are dependent on broader definitions of technology. McGinn (1978) argues that technology can be defined as a purposive process with an end goal that utilizes or generates knowledge. Similarly, Mitcham (1994: 159) highlights distinctions between 'technology as knowledge, technology as activity and technology as object'; a stance echoed by Arthur (2009: 9) where technology is defined as 'a means to fulfil a human purpose ... as a means, a technology may be a method or process or device'. Teaching and learning use methods and processes which involve practices and interactions within the socio-technical system or culture of learning that already exists (Osterlaken 2015).

Actor Network Theory (ANT) (Callon and Latour 1981; Latour 1987; Law 1994) describes sociotechnical systems as connections of heterogenous actors and actants (human and non-human) and views teaching and learning methods as an actant within a dynamic system. In ANT all (human and non-human) components in a network are considered actants/actors in what Latour (2008) calls 'Assemblages of the Social'. This means that an Actor Network is assembled for a purpose or goal (see Callon 1984) and can be made up of: 'agents, devices, texts, relatively standardised sets of organizational relations, social technologies, boundary protocols, organizational forms - any or all of these' (Law 1992: 385). The assumption here is that human actors are not privileged over non-human actors in what Latour (1987) calls symmetry or symmetrical analysis.

To be included in a network, the actor must do something. In ANT writings the notation Actor is given to human actors and to non-human actors, so it is perhaps more useful to use the term actant which ascribes agency to both as they act on others once they are established in a network. A change of an 'actant' will affect other actors within a network (Latour 2008). It is the effects of this 'actant switching' (Foley and Lockton 2018) of PBL into an existing teaching and learning system predicated upon standardisation of outcomes, lectures and knowledge tests, that this paper seeks to identify. How far did the switch to more participatory methods affect learner agency and self-organisation and did it result in any changes to curriculum or assessment?

To do this, the paper draws on findings from semi-structured group and individual interviews with staff and students who responded to the research question: What evidence is there that PBL and Flipped PBL methodologies give rise to a range of behaviours that can develop autonomy and agency within and outside the learning environment? The extent to which PBL can claim to be a transformational actor within the Palestinian educational context is addressed through a retrospective analysis using ANT. In addition, any increase in opportunities by learners to exercise agency freedom (Sen 1992; Robyns 2005; Nussbaum 2011) is examined as a key part of the intervention. According to Sen (1992), agency freedom is the ability of individuals and groups to choose a life that they value by converting capabilities into functioning - which in part is affected by contextual factors that can either support or hinder that conversion. 
A constant contextual factor in Palestine is continuing occupation and control by Israel. The Palestinian context is characterised by low graduate employment and outsourced working, coupled with the contested space restrictions on travel within, into and out of the West Bank. This can result in very localised university populations as travel, even over relatively short distances, can take many hours due to checkpoints and other restrictions. For many graduates the answer to the occupation is to leave the country and over $50 \%$ of Palestinian graduates find work outside of Palestine (Yahya 2016). The occupation makes education both a vital commodity and a promise of better things to come. As Fenwick (2012: 20) notes, learners can be positioned in terms of 'continual deficit and learning activities as preparation for some imagined ideal'. In Palestine it is arguable that this reinforces the need for an education system that focuses on standards and results determined by alignment with an external focus rather than the contextual needs of a population under occupation. Whilst the occupation itself is an actor within Palestine and beyond and is contextually pervasive, the scope of this paper is limited to the Actor Network within a specific teaching and learning context. As such, an Actor Network is bounded through its actors and should include all of the elements of curriculum, teaching and learning and assessment. According to Graff and Kolmos (2003: 658), 'changes in one of the elements involves changes in all the other elements'.

\section{Background and Context}

Why Actor Network Theory?

Actor Network Theory is often conceptualised as a tool for analysis of a particular situation rather than as a model to be applied generically (Cressman 2008). In essence it is about the ethnography of networks and follows 'the actors' within a network to see how they interact in any given situation. Actor Network theorists see networks as socio-technical or heterogenous because all human and non-human actors in a network have agency (Cressman 2008). Latour notes that:

Without accounts, without trials, without differences, without transformation in some state of affairs, there is no meaningful argument to be made about a given agency, no detectable frame of reference. An invisible agency that makes no difference, produces no transformation, leaves no trace, and enters no account is not an agency. Period. Either it does something or it does not. (Latour 2005: 53)

People, technologies, texts, and even the ideas and ideologies they represent can be equal actors within a network. Aligning oneself with this shift in perception is difficult and perhaps the best example is Laet and Mol's interpretation of the agency of the Zimbabwean type B Bush Pump.

The Zimbabwe Bush Pump is easy to love. Not only because it provides access to clear water for many people in rural Zimbabwe - which is certainly a good thing. But also, because, in the way it does so, it teaches us something crucial about the kind of actorship that technologies may take upon themselves. ... The Pump is a mechanical object, it is a hydraulic system, but it is also a device installed by the community, a health promoter and a nation-building apparatus. It has each of these identities - and each comes with its own different boundaries. (Laet and Mol 2000: 29).

Laet and Mol (2000) define the pump as an actor within a network that has different qualities and communities of use. Within this network, different actors are involved. For example, the network has an inventor/actor who supports its continued development and gives away the intellectual property so the pump can continue to be built by a variety of companies. In order to gain the health benefits of clean water, the pump needs people to install and maintain it correctly, so the pump is agentic in building a community. The pump can keep providing 'goods' in the economic sense even when one of its functions is lacking - for example, it may provide health benefits in the dry season rather than in the rainy season when the well may become contaminated by surface water running into the water course. Laet and Mol call this 'fluidity': an actor can fail in any one of its actant roles but still continue in others. Such a technology is adaptable to context and purpose whereby it can recruit other actors to its use for different purposes and goals.

In the context of PBL one can see similarities with the Zimbabwean Type B Bush Pump's notions of fluidity and adaptability. These are affordances of an actant acting as a mediator in ANT, where technologies do not function as passive objects and simply pass on some effect from one actant to another but transform situations and produce effects and outcomes in others (Beuger and Stockbreugger 2017: 8). There are, for example, many types of PBL (Savin-Baden 2014) even to the extent that there are often other names for similar processes such as project- product-, or enquiry-based learning. PBL in essence is a scaffold of instructions that students and lecturers can follow intuitively rather than a complex method that they have to learn and internalise. It is this simplicity of form (see Polya 1957) that contributes to PBL's fluidity or its ability to adapt to different contexts. In education the terms scaffold and framework are often used interchangeably, yet in other fields such as architecture and design there is a clear distinction in meaning. 'A framework is a complete structure, usually permanent and gives form to that which it supports or encloses or solves. A scaffold, on the other hand, is a 
temporary structure for supporting something until that something is able to stand on its own.' (Pendleton-Jullian and Brown 2018: 272)

PBL as a simple scaffold supports different forms of adoption and use ranging from academically situated issues to complex problems that do not have a single correct answer. A problem can be theoretical, practical, social, technical, or scientific, and is usually based on real life issues edited to meet educational objectives but can extend to student determined problems (Graaf and Kolmos 2003: 658). Different approaches to PBL can be characterised by the degree of agency they concede to learners and the reciprocal amount of control educators give up. Like the Bush pump, which creates a community and roles for pump fixers and maintainers, PBL also acts on its participants' roles and identities (De Graaf and Kolmos 2003: 658).

\section{Recognising the actors}

Actors in a network can also be 'black boxes' (Law 2007) where complex networks themselves are imported whole into a system (often likened to a TV or a car) and the actant is not reopened or questioned. It functions within the network and 'does what it does'. 'A black box contains that which no longer needs to be considered, those things whose contents have become a matter of indifference.' (Callon and Latour 1981: 285) When received or established teaching and learning methods in higher education are routinely (rather than reflexively) enacted, they might be thought of as black boxes, seldom opened for fundamental review, even though they are routinely enacted. In this regard the black box of PBL is slightly different and more akin to a Lego set: you open the box and see how you might build something that fits and adapts with your existing construct. Agentic intent is built into the design of PBL by those who propagate its use. The key principles, ideas, and ideologies embedded in the PBL design employed in the METHODS project were based on the work of De Graaf and Kolmos at the University of Aalborg, which was a METHODS project partner. These include:

a problem definition process coupled to learner self-direction which builds on learners' prior experience; activity based learning and decision making; the interdisciplinary nature of 'real world' problems which can extend beyond traditional subject boundaries and methods; exploring complex problems at a system level; and group based activities so that personal competencies are developed and students learn to handle the process of group co-operation in all its stages. (De Graaf and Kolmos 2003: 658)

Further actors in the METHODS project network were PBL theorists and designers who had trialled and tested their design over many years and had working examples to show to participants in the project. The METHODS project recruited the practice of both students and teachers at the University of Aalborg and their model/operating instructions (Ryberg et al. 2006) (see Figure 1). The ability of Palestinian educators to visit and experience the model first-hand was an actant in the network which meant that they were recruited to the network as actants themselves who would push in favour of an acceptance of PBL.

\section{PROBLEM BASED LEARNING AT AAU $_{3 / 3}$}

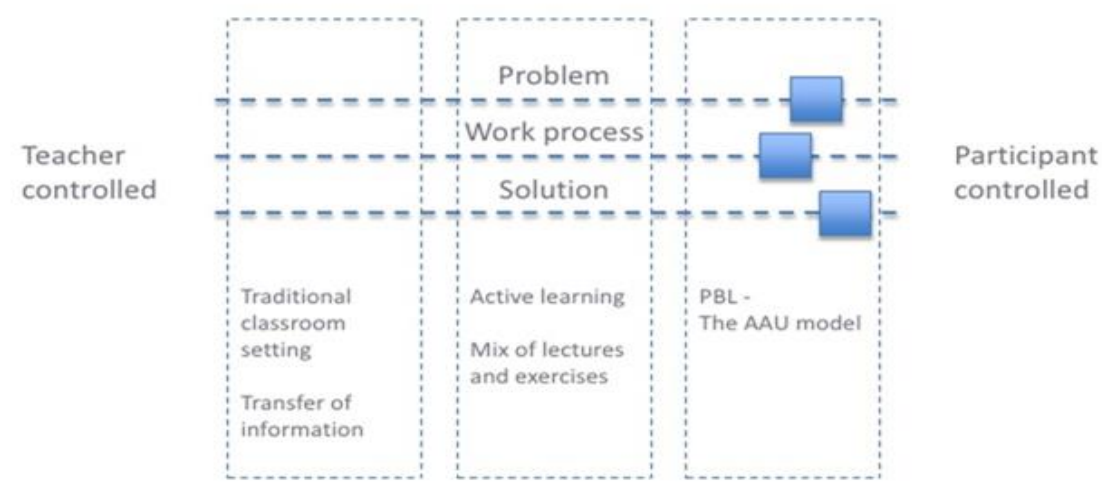

Figure (1): Problem based learning at Aalborg University (Magnussen 2016)

The Aalborg model presented in Figure 1 allows a range of approaches that lecturers can fit to their particular learning context. This is pertinent to the Palestinian higher education environment where practices in each institution can be distinct due to restrictions on travel that can make these practices, even in such a small area, highly independent of each other. EU sponsorship of the METHODS project could also be considered an 
actor with the role of legitimising the project in the eyes of participants and easing its passage with expertise, prestige and funding. The METHODS project itself was modified by key human actors who changed its original emphasis on e-learning by incorporating PBL as a project objective. Further actors, those in charge of academic regulations in the Palestinian institutions, were recruited to the network through the provision of funding and the project's status which embedded the project further. This meant that administrators within universities were able to facilitate and allow modification to existing processes such as assessment - that worked with the PBL implementation to effect change.

\section{Bounding the system for analysis and change}

The METHODS project sought to act across a broad range of courses. In the Palestinian context this resulted in four Universities with 21 different and distinct courses where PBL was introduced as a new pedagogic approach. One of the first acts with an ANT retrospective is how to bound the system under study - this is in part the process of recognising the actors/actants in the network and how is it constituted. Pendleton-Jullian and Brown (2018) use the analogy of the ecosystem which is made up of smaller subsystems called ecotopes. In this case we could say that each university is the ecosystem in which smaller ecotope subsystems exist. Each ecotope is possibly the faculty in which each course is taught but from there we can go further to look at the actual course itself as a subsystem of the whole. All of these systems are influenced by external factors and relationships that are unique to them, but all also share common interests and perspectives in that they are all higher education courses and all part of the METHODS project. In this method, the network is already extant and all that we need to do is draw a line around the areas that we want to study. Conversely the boundaries of an Actor Network are created by the actors and actants who are invested in the 'problem or goal' through the act of 'translation' which is the act of recruiting new actors into a new or reformed network and through that, establishing its boundary (Callon 1984). Those included are those that act.

The diagram in Figure 2 sets out the main boundaries using the ecosystem approach (Pendleton-Jullian and Brown 2018) and delineates some of the situated actors, that may form a network in this educational setting. It must be noted that boundaries are not static and can move and blend into others, but they are constructed here for the purpose of analysis in the context of the METHODS project. Fenwick and Edwards (2012: 6) note that 'representations of networks are themselves concrete, implying the realities to be far more stable and durable than imminent, precarious shifting socio-material relations ever can be'.

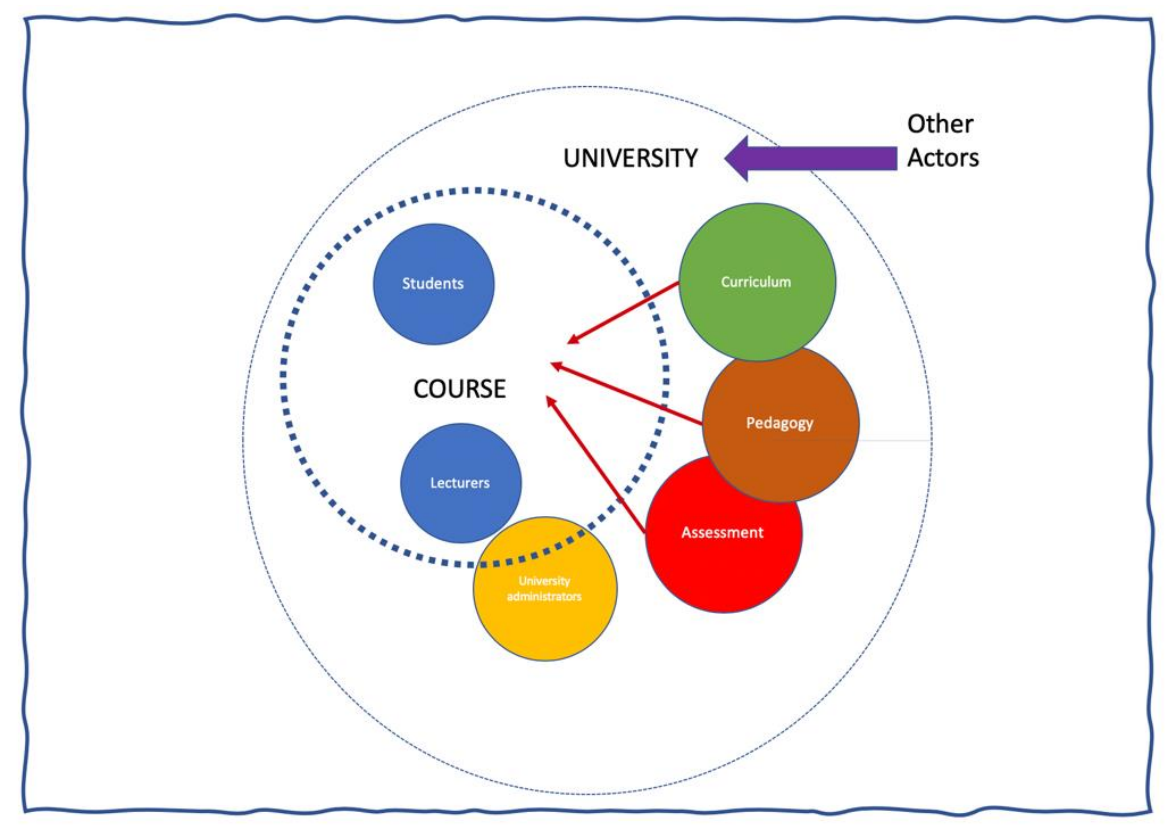

Figure 2: Initial drawing of boundaries and Actors within the Methods Project PBL intervention.

The diagram shows the boundaries of various systems and where the actors are located within them. It also notes that there may be other actors that may set constraints on activity and influence the other actors within the system, thus 'the Occupation' may also be an actor within the system as far as it constrains or enables the educational culture. According to Law (1988) these actors can be written in as social 'black boxes' depending on perspective, depth and extent of analysis. The clearly defined actors articulated within this analysis of our network are the students; the lecturers; the university administrators; and the techniques (Arthur 2009) of education (curriculum, pedagogy and assessment). Although definitions of technology are contested (see Ingold 2000), 
technique(s) is equated to a process or method (a means to an end) and as such curriculum, pedagogy and assessment are included as a 'technology' in that they are methods, processes or devices with a purpose after (McGinn 1978; Mitcham 1994; Arthur 2009).

Within the techniques of education there are several 'black boxes'. All educational courses operate within a conceptual understanding of what education is. However, the interpretation of this is often tacit to the practitioners so it remains opaque, unarticulated and often taken as a given. The black box of education may be opened by using Bernstein's (1975) notion of three elements in the educational construct - curriculum, pedagogy and evaluation - which, he argues, are used as message systems of socialisation and control. Without going into the nuances of his argument which are covered in adequate detail elsewhere (Cause 2010; Gibson 1977; King 1981; and others), we simply borrow Bernstein's (1975) construct through Cause's (2010) interpretation: through these three message systems of education, the dominant cultural group controls, classifies, produces and transmits what knowledge is to be learnt and what values and attitudes are acceptable in that society. Thus, any change in any one of these three elements or message systems could have an impact on the other two as they are dependent on each other. Graff and Kolmos (2003: 659) also use the notation of curriculum structure, learning process, and assessment, insisting that if one changes all must change by design before implementation.

However, Pendleton-Jullian and Brown (2018: 286) note that 'the agents within a system are so interdependent and interconnected that all actions taken affect the system which changes the context and changing the context changes the problem, recreating the context anew'. In this light, notions of curriculum, pedagogy and assessment can be added to the Actor Network which is constituted with both human and non-human actors. In Figure 3, the new entrants to the actor network are: the METHODS project; training events; Aalborg ideas; and PBL. These new entrants act on both the existing human actors (students, lecturers and administrators) and the non-human actors (curriculum, assessment and pedagogic practices). The latter can also include processes, frameworks or scaffolds, indeed mechanisms (Pendleton-Jullian and Brown 2018: 281) and black box objects.

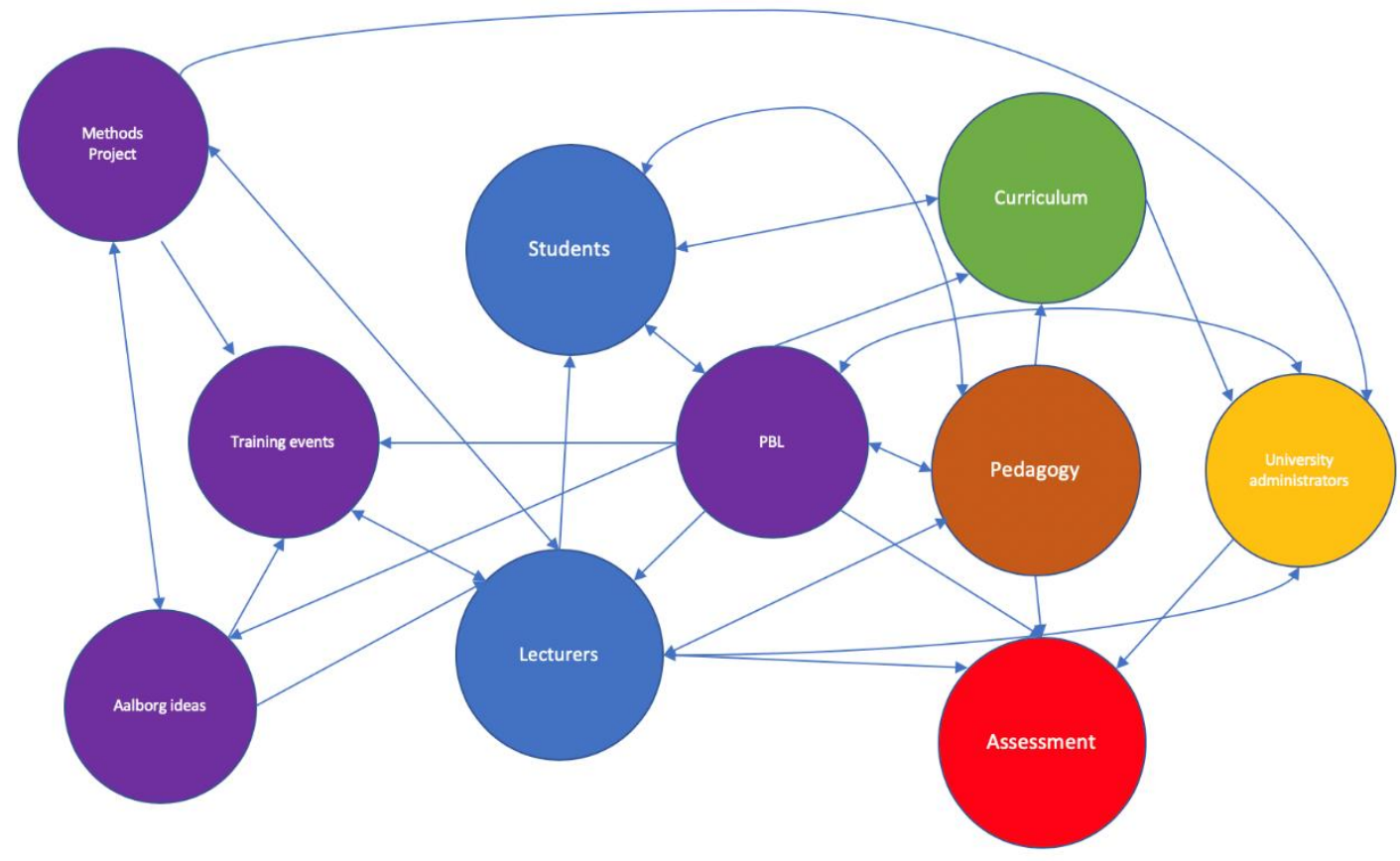

Figure 3: The Actor Network is developed to include new actants (Methods Project, Training Events, PBL, Aalborg ideas)

A system for analysis is bounded by the actants in the network presented in Figure 3. An additional factor to consider is Latour's (2008: 39) classification of actants as mediators or as intermediaries where the latter '[transport] meaning or force but without any transformation: defining its inputs can define its outputs'. Here an analogy can be drawn to a curriculum (knowledge base) that replicates itself through its pedagogy (instruction) and assessment (result). The message of society is transmitted and there is little possibility of transformation as all is fixed in place and immutable (Bernstein 1975). Conversely, argues Latour, when an actant is a mediator, the situation becomes transformative. 'Their input is never a good predictor of their output; their specificity has to be taken into account every time. Mediators transform, translate, distort, and modify the meaning they are supposed 
to carry.' (Latour 2008: 53) How far PBL acts as a mediator and how far it effects other aspects of the network will be considered further in this analysis.

Defined as the range of possibilities for action prompted by an object within a context and how humans perceive that possibility, the notion of affordances (Gibson 1977; Norman 1988) is important for this analysis. Latour (2008: 72) notes that 'things might authorise, allow, afford, encourage, permit, suggest, influence, block, render possible, forbid and so on'. Norman (2004: 1) gives the example of clicking on a computer screen and says that an affordance of the object goes beyond clicking. The object is clickable, but the real affordance is to do with perception. Does the user perceive clicking on that location as a meaningful, useful action to perform? This is similar to Latour's concept of mediator versus intermediary. Does the affordance of the object or technology allow other actors to do something that is meaningful for themselves? Does the affordance of the object or technology prompt or release agencies in that and other parts of the network that affect change?

\section{The affordances of PBL as an actant}

Polya (1957) devised four universal principles to directly address problem solving: understand the problem, devise a plan, carry out the plan, and look back. Problem solving is a plan without a context or content and this absence makes it both sticky (Gladwell 2015), likely to be adopted, and agentic. PBL invites participants to create and engage with their own problems and issues in their context by researching and adding content, ideas and plans for action. The Aalborg training module is decidedly thin on content and is merely a set of statements to which educators supply their own answers where the problem is the starting-point in the learning process.

- The starting point for learning should be a problem, a query, or a puzzle that the learner wishes to solve.

- Complex problems that do not have a single correct answer - often (based on) real-life problems.

- Learners should build on their own experiences and learn through active engagement with cases or realworld problems.

- A problem can be theoretical, practical, social, technical, or scientific and grows out of students' wondering within different disciplines and professional environments.

- $\quad$ Students research and decide on solutions. ( Graff and Kolmos 2003: 658)

PBL in this context is a method that affords, authorises, allows, encourages, permits, suggests, and invites agency (Bandura 2001) from both lecturers and students. The learning design gives people a measure of control over their own functioning and environmental events and encourages both diversity of approach and outcome. Agency is often co-located in educational terms with the notion of perceived self-efficacy, defined by Bandura (1982) as being concerned with judgments of how well one can execute courses of action required to deal with prospective situations. Cauce and Gordon (2013) note those with a strong sense of self-efficacy are most likely to persist in the face of failure. Therefore, it follows that self-efficacy can be brought about by practice and by putting people into situations where failure and overcoming failure through perseverance are part of success in any endeavour. This is a particularly pertinent asset for living and working within the Palestinian context, which creates clear limits within which agency can be applied.

Sen's (1985: 203) notion of agency freedom refers to 'what a person is free to do and achieve in pursuit of whatever goals and values he or she regards as important' and this has resonance to the context of occupation. Palestinian students live a constrained experience as a lecturer at Bethlehem University (2018 interview transcript) demonstrates. 'In Palestine you are going to have days where movement is very difficult, but we need to continue. We live in a precarious environment.' Students from Birzeit University, Ramallah, also voice similar issues: 'Sometimes they (Israel) close the roads so we can't go (to the university).' 'Last year, because of the intifada ... Those that come from Jerusalem could not reach the campus safely.' (Royle and Scott 2018) Tobias (2005:70) notes ' $[\mathrm{t}]$ he reification of agential freedom abstracts from the concrete context and conditions under which chosen ends can be effectively pursued'. Although ANT focuses only on those who act, it is also important to keep the lived experience of Palestinian lecturers and students in mind.

\section{PBL as mediator and transformer}

Within the safety of the course space, made open and diverse by the PBL actant, all things are possible in a rehearsal and exploration of authentic complex issues through speculative design (Dunne and Raby 2013). Here student actors can create 'what if' hypotheses for change and transformation. In so doing, personal and collective agency is released by PBL through self-organisation (Savin-Baden 2014) and students work together to develop solutions to emerging problems through co-construction of meaning, convergent and divergent discussions, listening and negotiation (Bossche et al. 2006).

In the METHODS project, problem formulation was not context-free but tended to use student experiences and issues from the Palestinian context aligned to academic disciplines. Students saw problem formulation as an opportunity to include their lived experience. For example, electronic engineering students decided to create power supplies for West Bank schools so that they could use donated technology more 
effectively. PBL allowed real world problems derived from the students' context to enter the educational space by recruiting the external context as an actor rather than as a silent partner that is constantly beyond the gate. PBL therefore acted on curriculum by making it look for context and authenticity within which to place its knowledge and skills. With the outcomes also shifting through students being able to choose a variety of problem-solving methods, assessment techniques needed to become more intelligent and transformative. The University administration suddenly found itself accommodating radical shifts in pedagogy and mediated changes in assessment regulations. The pedagogy of PBL clearly started to affect changes in curriculum and in assessment.

PBL as an actant for self-organisation

A key additional attribute inside the PBL black box is its ability to sustain engagement and nurture collaborative behaviours. This is not a natural process of biological self-organisation such as a school of fish or a murmuration of starlings, but a process set in motion by an actant.

In self-organizing systems, pattern formation occurs through interactions internal to the system, without intervention by external directing influences... Systems lacking self-organization can have order imposed on them in many different ways, not only through instructions from a supervisory leader but also through various directives such as blueprints or recipes, or through pre-existing patterns in the environment (templates). (Yates 1983:1)

PBL provides a scaffold or template within which agentic self-organisation can flourish and establish itself. Brandt (2016) outlines the factors necessary for self-organisation to take place in the triangle of self-organisation represented: a goal or vision, a set of rules or guiding principles, and an imperative or motivational aspect (see Figure 4).

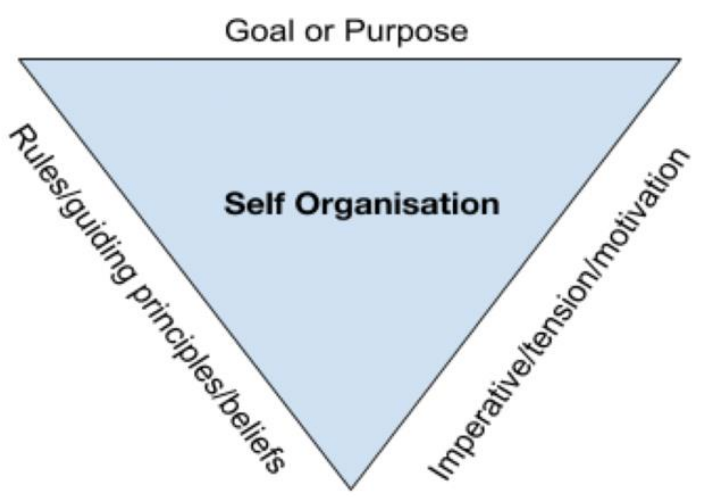

Figure 4: The triangle of self-organisation, (after Brandt 2016)

PBL provides guiding principles, a goal (finding a solution to a problem) and motivation both through the extrinsic formal need to pass the course but also intrinsically because the problem/goal is chosen by students. Further consideration of PBL in the METHODS project and its role as a mediator in an Actor Network leads to the modification of Brandt's model. Here the actant of PBL is the mechanism which is central to the creation of the process of self-organisation. PBL has supporting values or rules, requires a solution or goal, and creates multiple and more or less defined outcomes. PBL also draws in and creates motivations through personal engagement and choice of problem / solution in a two way process. PBL is supported and endorsed for the educational environment by existing theories (much like the Bush Pump designer's specifications). Moreover, PBL is free to use and not expensive to implement because it does not require handbooks, prescribed steps, or professional certification. 


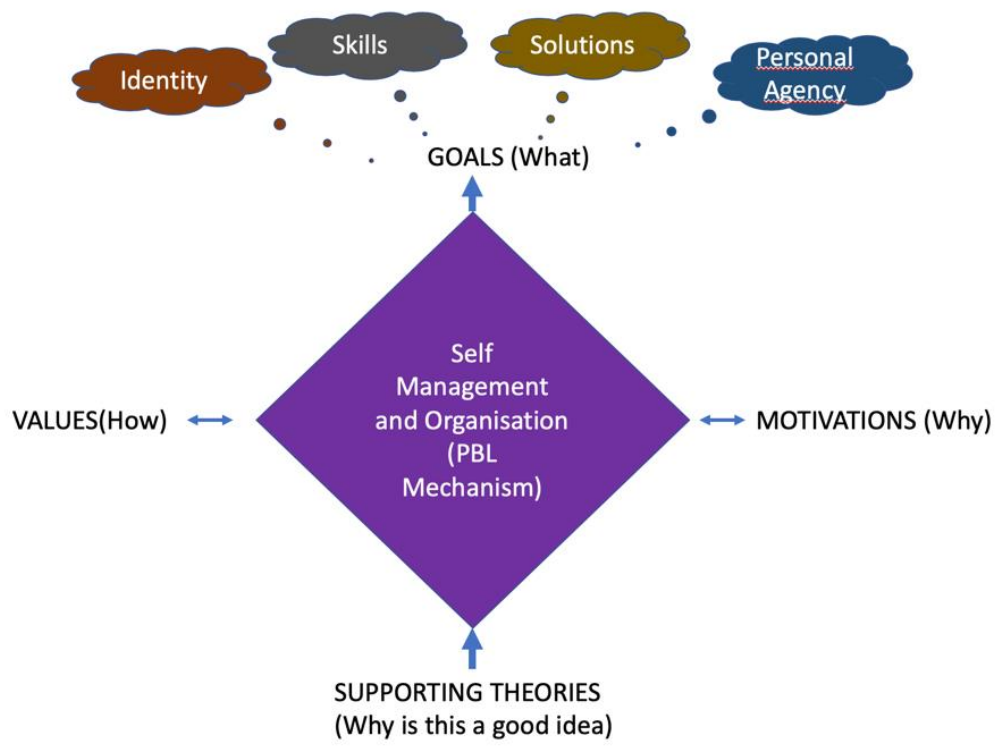

Figure 5: PBL as a mechanism of self-organisation.

Figure 5 delineates the components of PBL that make it agentic. The technique or mechanism of PBL as an actant in a network is defined. This is an issue of granularity - of looking inside the actant of PBL and examining how it achieves the change at an operational level. Pendleton-Julian and Brown (2018: 281) describe mechanisms as 'things that do work. They are the things through which an effect is produced, or purpose is accomplished. Mechanisms are often processes or techniques that operate at the tactical or operational level'. Whilst Pendleton Julian and Brown suppose a human actor using a mechanism, ANT bestows agency to the actant because its presence has an effect on other actors. The idea of mechanism, and how it works, allows that the workings of the actant are made visible and the black box of PBL - as the agent of self-organisation - is unpacked. We can now look for the products of self-organisation in any evaluation of PBL as actant. In particular, what changes are evident in other actors within the network as a result of PBL's work as a mediator - actant?

\section{Evidence of transformation from the methods project research findings}

This section reviews the interview findings to determine how far PBL has been able to act as a mediating actant of transformation in the METHODS project. ANT was not used in the research and is applied retrospectively to see what insights it can discover from the responses to interview questions detailed in Royle (2019). Qualitative group (students) and individual (lecturer) interviews were used to gain insight into the effect of PBL across a range of stakeholders and their accumulated body of knowledge about their lived experience of the intervention/learning design (Chilisa 2005; Royle 2019). Students took part in semi structured group interviews based on a bespoke interrogative framework. Ten staff were interviewed individually to gauge their views on the effects of PBL. Students were interviewed over a three-day period in April 2018 and the sampling method was that of convenience.

Although there are selection bias issues with this type of sampling, it could be argued that the sample was a homogenous group and consisted of a mix of gender representative of the overall university population of around $60 \%$ female and $40 \%$ male. Also, all participants were invited to take part. The sample consisted of 27 students at four different Universities comprising Birzeit University (BZU) (Ramallah) ( $n=5$ ), An Najah University (ANU) (Nablus) ( $\mathrm{n}=8$ ), The Palestinian Polytechnic University (PPU) Hebron ( $\mathrm{n}=8$ ) and Bethlehem University (BU) $(n=6)$. The students were interviewed in cross subject groups in ANU and PPU and single subject groups in BZU and BU. Communication between the groups was not possible and it was interesting to note the similarities of response despite the variety of courses that the students were drawn from. Students and teachers from the following disciplines were interviewed: Electronic Engineering (Birzeit); Systems Analysis and Computer Systems Engineering (Bethlehem); Teacher Education Bethlehem, Land Use Planning, Ecology, Literature, (An -Najah, Nablus) Methods of Scientific Research (Hebron). All courses were undergraduate.

The group and individual interview transcripts are regarded here anew to articulate whether the affordances inherent in PBL allowed the development of: a range of soft skills necessary for functioning in a selforganised environment, increased agency freedom by extending choices for learners, curriculum modifications as a mediator of authentic content, identity formation in lecturers and students (Oosterlaken 2015), more diverse assessment methods, and administrators' willingness to act to transform learning and teaching at the university. In addition, to validate an element of self-organisation there should be evidence of goal setting, motivations, and 
of planning mechanisms and techniques being used. By opening the black box of PBL to see what is 'under the hood' there is a means to seek evidence in respondents' narratives of some of the affordances of PBL.

Evidence of PBL as a mediating actant

Authentic tasks and real-world problems change the nature and scope of curriculum where subject knowledge is applied to a real situation.

The most important experience is that we implemented electronics in the real world for the first time. It was amazing, now you can understand lots and lots of things. Making applications in the real world with a real application not just doing something for the course. We saw the output. We are more confident because we can do stuff now. When I walk into a room now, I can look at anything and understand how it works. (BZU Student 1)

In one case a student referred to their work in teaching literature in Palestinian schools by remarking that the PBL process had made them realise that '[1]iterature is not a smooth subject it is rigid and we try to open it and make it more accessible' (BU Student 3). Students reflect about the fabric and nature of their subject and test how different approaches might bring these to life within authentic settings to solve problems within the wider construct of Palestine. Making, that could be applied to social needs, was seen as a positive outcome for the computer engineering course students.

We are developing power supplies for every school for them to do stuff with it. It costs 115 dollars normally. To power up computers and projectors. We take the power supplies from (redundant) PC CPUs and convert them. Low cost and allows the school to use a power supply for different things. So, we make this initiative for the people as a social obligation so we can give something back. To help them... (BZU Student 5)

Both students and lecturers remarked on the motivational aspects of having an authentic purpose. The theory became live and practice was hypothesised and tested. In one course at PPU students looked at using the waste from stone quarries to improve soil fertility which has since become a start-up venture. PBL, by drawing in real life issues, broadened the nature of curriculum selections which in turn supported the PBL learning and teaching method by providing a choice of problems to work on that had contextual meaning for students. Practical understanding and working things out for oneself replaced the more academic approach. Applying theory was seen as an effective learning strategy across a range of subjects.

I did not understand the concepts but when it was done in the practical sense it became easier for me. Getting knowledge about what you can't understand theoretically through practical work. This broke the barrier for me. (BZU Student 5)

Even the act of co-ordinating activity became an authentic learning experience that replicated the world of work.

It is difficult when you are cross disciplinary to get time together to complete projects. We used technology but we had to be together physically as a group too. (PPU Student 1)

Agency freedom through extending choices for learners

In Bethlehem, PBL shifted the locus of control and increased participation and the confidence of students engendering a belief that they could achieve things.

We didn't feel like students it made us more confident - we do things not receive them. I have become more confident in presentations and how to work with people. (BU Student2)

In Nablus (ANU) students spoke of 'Self confidence in my own abilities':

Before this course I did not have the powers to stand and discuss with students. Now I can speak and discuss with others. We are more confident, we felt interested and proud because we had achieved something. (ANU Student 3)

PBL encouraged individuals to develop new skills and shifted control to the students by giving them a measure of control over decisions. They perceive the affordance of taking part in research and what that means for their self-development. It opened new possibilities and nurtured capabilities into valued functioning. 
Systems analysis taught me research skills I should look for information myself and not depend on teachers. This was really important for me. To think and build something on your own is important. (BU Student 6)

PBL also opened space for speaking up and speaking out within the bounds of the subject extending the opportunities for the development of critical thinking.

When you do this kind of class, you do things, you give your voice, you write your opinion, you suggest, you make something, you say what you think and then if you think it is true you have to prove it through practice. (BU Student 3)

PBL encouraged learning through failure and belief in one's own self-efficacy (to achieve things), encouraged perseverance and a willingness to try and find what worked in their context.

We tested hypothesis as we practised so failure is part of the plan. BU Student 2

We didn't think about the grade only that we shouldn't quit. (PPU Student 5)

We changed our output 5 times... either because we were giving the wrong solutions or the wrong causes

for the problem. So, we had to revise and do it again. (BU Student 3)

PBL employs mechanisms and techniques of self-organisation that allow students to experiment with uncertainty and develop soft skills. This requires both participation and motivation through choosing an area of investigation and participating collaboratively in a team. PBL scaffolds and encourages this participation often against students' actual preferences as a lecturer noted:

We get an inflow of students that are very traditional with this type of lecturing - indoctrination, exam based. This continues in the university. The students put high pressure on their teachers against any new approach. It's challenging to move the students from teacher centred to student centred. It's not easy to change existing learning habits and expectations. Learning is harder this way. They expect you to transmit knowledge and when you flip the roles it's a bit of a shock. (BU Lecturer 1)

The planning and goal setting afforded by PBL also scaffolded motivation. Ways of thinking were also purported to have changed:

We started to use critical thinking and started to think like an analyst to solve problems. (BU Student 6) The work was fun, so it wasn't really hard. We enjoyed it more, we are applying and testing theory. So, it sticks in your mind. We also reflected a lot. We took part in self-evaluation using the rubric. (BU Student 3)

PBL developed teamworking and collaboration and brought about opportunities for developing skills in negotiation, conflict resolution and mutual support.

We had discussions about what to do and we all agreed after negotiation - We learned a new set of skills around practical and communication skills, we had to adapt to having a new partner who we had to train. (BZU Student 1)

New insights were gained into working collaboratively in teams and the students realised that they had to solve any problems that arose and use soft skills to do so.

The team is most important and sometimes some members don't work but we solved it. You should try to choose your team well. - We had some issues, but we made each other work. (BU Student 6)

Mutual support was also evident:

For me this course improved my personality so much...how to work with others...communication, conflict solving, co-operation which made us more effective in group working- we learned more because we worked together...we connected with each other and also helped students who were not advanced. (ANU Student 2) 
Students commented on how much more involved they were in classes. Increased participation was a key aspect of the actant (pedagogy) switch.

When you go to a regular class you just take whatever the teacher says, you don't understand the whole thing ... you only get about $70 \%$ of the information that you need to actually comprehend everything. You just sit in class and listen. In the methods project we contributed. (ANU Student 5)

We were more active as students and less passive. We are not receivers we are producers. (PPU Student 6)

They also commented on discussions and the benefits of working with the lecturers and students.

Each stage of the problem-based learning was discussed, and we got feedback from her (lecturer). Difficulties and improvements. It's the only class where I never felt bored. (BU Student 3)

They expressed feelings about this way of learning. 'It's fun' was mentioned regularly in the transcripts across all the Universities and courses.

\section{Identity formation}

Students claimed that they were thinking differently rather akin to Gee's (2005) conceptualisation of 'authentic professionalism' where experiences transform individuals into becoming researchers or engineers or teachers. Students took on more professional positions in regard to how they thought of themselves and also around how they worked with their lecturers. Students said that they felt like 'researchers or engineers and real teachers'. They thought the lecturers were friendly and approachable, like team leaders or colleagues. Barriers seemed to disappear, and communication became easy. PBL also developed lecturer identities.

My role changes from a teacher, (I act as) a supervisor and as a consultant when they design something, I advise them to review their solutions. (ANU Lecturer 2)

Biggest change is that you are closer to the students, friendlier...in the classical one the students are far from you but in this you are sitting with them, talking, close face to face, discussing and you are like a friend rather than a teacher. (ANU Lecturer 3)

Assessment

PBL causes diversity of outcomes which doesn't equate with a single form of assessment.

At the end they all came with different solutions to the same problem which was great and unusual. (BU Lecturer 3)

PBL authorises different assessments. Several lecturers expressed 'pride' in their students' achievements and how much the students enjoyed the approach. This required a different mode of assessment.

Grade averages came up from $\mathrm{C}+$ to $\mathrm{B}+$ but I changed the assessment. I was shocked that they understand so well and... I have become a good teacher.

The students were amazing, and their work was a very high standard. They related their solutions to the context of Palestine and chose the best one. (PPU Lecturer 2)

Some students at Birzeit expressed dissatisfaction because the assessment had not changed because they had '...already proven their knowledge of the subject through the project work. We will take the exam but why bother?' Several lecturers remarked that the quality of work and engagement had increased but several realised they had to change the mode of assessment.

I also tweaked the assessment to ask them if they wanted to be evaluated as a team or individually. Also, peer evaluation and we discuss the assessment, so we introduced democracy to the grading process. (ANU Lecturer 1)

I changed the assessment so less writing and more technology-based products, presentations. PPT and videos. (BU Lecturer 3)

\section{Mechanisms}

PBL is both fluid and sticky (adaptable and easy to grasp) because it creates a plan without a context or content and encourages customisation to a subject and their contexts. 
The framework we used is from the Aalborg PBL training in UK and when you are a practitioner it just clicks. (Lecturer 1 PPU)

Lecturers devised a range of mechanisms to scaffold students' work and guide them towards self-organisation. PBL does not set out to create self-organising teams but has the essence of self-organisation sitting within it. All lecturers used some form of scaffolding mechanism. and while some consisted of content with providing a problem-solving rubric, materials, and regular meetings for discussion, others created detailed assessment frameworks and project plans for students.

I then used PBL...I gave a structure to students and they worked in groups and each month they presented their work. Each group had a use case given by me and they applied it in their group. After 1 month they have to present the progress. They thought it was a lot of work. (BU Lecturer 3)

Another lecturer used clearly defined stages to scaffold the work of the students.

It was a lot of work for them, trying to identify problems, going into the community trying to test your solutions. There were stages and they did it in three stages.

I was able to meet them at each stage and guide them through...I also told them it was okay to fail. (BU Lecturer 1)

Each tutor had a different mechanism for structuring the learning, a fact which reinforces its fluidity.

This is much better for them. I had regular classes but only for project discussion. I advised them in these sessions. (ANU Lecturer 1)

\section{Letting go of control}

PBL permits a flatter structure to develop than in more didactic methods of learning. PBL creates a context where learning is negotiated, and hierarchy is less important. In some cases, the lecturers felt it was more democratic and the power dynamic in classes shifted.

We loved the way that the student and the teacher are the same level. (ANU Lecturer 3)

Students stopped being passive receptors and became actors and mediators themselves in broader networks. Lecturers noticed this release of agency within the students and themselves:

Seeing them collect data, engage with the texts, complain to me and fight sometimes with each other...that was a transformative experience for them. (PPU Lecturer 2)

They were structured around teamwork and dynamics and negotiations. It's worth it even if it fails. BU Lecturer 1

We see the lecturers as guides and this way we have more control and power. We developed new skills. (ANU Student 5)

These latter statements illustrate the transformation and movement of control from the lecturers to the students and overall it can be noted that PBL has transformed the relationships not only between lecturers and students but also between pedagogy, curriculum and methods. Moreover, PBL has enabled students to have more choice about what they learn and how they process learning.

\section{Discussion}

Understandably, Palestinian education is bounded by the power relationships with the occupier and conforming to academic norms and 'standards' is important for credibility, especially where comparisons may be drawn with others. Change in any environment comes with risk and this is perhaps why methodologies become fixed/orthodox in spite of the fact that other forms of education may address the context of occupation more effectively. The use of ANT allows the key components of change in this instance to be made manifest (Law 2003). Rather than just focusing on PBL and lecturers and students, which might be the limit of a conventional analysis of the intervention, other actants, often driven by different reasons, were made visible as contributors to the network that enacted PBL as a mediator. A wide variety of human and non-human actors, from training events to texts and ideas were enlisted to create the placing of PBL as an actant for change within the education message systems of curriculum, pedagogy and evaluation.

A large circle could be drawn around Figure 3 and Figure 4 and labelled the ecosystem of occupation but this may not have helped analysis. As Fenwick and Edwards (2012: 6) note 'Wherever one marks boundaries 
around a particular phenomenon to trace its network relations, there is a danger of both privileging that network and rendering invisible its multiple supports'. In this study, the occupation is always present in everyone's lives and in the way that it forms and influences Higher Education's striving to be the 'best' in spite of the occupation. However, in the Actor Network described here the occupation does not act directly. Instead, the network acts within the context of occupation and this may be one of the reasons why PBL takes root so readily within the Palestinian context. The occupation is effectively black boxed and whilst not forgotten is not explicitly referred to. In ANT, such an actor demonstrates absent presence whereby it is made manifest by its absence (Law 2003). Occupation is included in the ontologies of the other actors and the outcomes of the PBL project could all be seen as potential ways of either acting back against the occupation or acting positively in support of Palestinian endeavours.

Within and across the institutions and courses of the METHODS project there is evidence that PBL did transform, translate, distort and modify the meanings it was supposed to carry (Latour 2008). The pedagogical switch from existing methods, a form of actant switching (Lockton and Foley 2018), affected the central part of Bernstein's (1975) three elements of the educational construct directly, changing its form from intermediary that 'transports meaning or force but without any transformation' (Latour 2008: 38) to mediator. Not only did the project change the pedagogic element significantly; it arguably affected both the formation of curriculum by incorporating issues and problems from the Palestinian experience and the evaluation regime towards an evaluation of process as much as outcome.

Seeing PBL as the mediating actant also allowed an investigation of that particular black box of teaching and learning. A move towards learner centred design requires participation through a degree of self-organisation (Brandt 2016) and the conceptualisation of this as a mechanism within PBL is important. It is this combination of goals, imperative and rules for taking part that releases and allows agency on the behalf of both lecturers and students. Roles and identities shift within the education space and arguably there is more freedom to choose a direction. PBL arguably leads to an expansion choice not only of what to learn but also how learning might be achieved. It is this degree of self-direction that may lead to the reflective act of questioning the purpose and direction of what is learnt. Students may quite rightly ask, 'Does this make sense within our current context and how does it lead to living lives that we value'? Where capabilities are converted into valued functionings, agency freedom (Sen 1992) appears to be expanded. This also has the effect of recruiting other actors to the network, as students reported using digital technologies for meetings and various research methods they previously may not have engaged with for those purposes.

PBL's mechanism of releasing human agency allows both educators and students to make judgements about what educational goals they would like to pursue. In a country under occupation, PBL enables the selection of projects based on solving issues collaboratively that arise in the oppressed communities of the West Bank. This may expand further in time to align the education curriculum with regenerative activities (Fullerton 2015). The idea of pedagogy as technology allows a replacement of the existing with the new, to see what happens. PBL as an actant was a direct replacement for existing pedagogical approaches which were established 'orthodox' methods. In speculative (nonfictional) design, actant switching (Foley and Lockton 2018) is used to examine whether replacing a human actor with a non-human actor has any effect on overall service functions and/or user experience. The whole of the METHODS project could be seen as a speculative design where didactic methods (a socio-intellectual technology) were replaced with another socio-intellectual technology that invoked learner centred agency. Both techniques were non-human actors with different affordances and PBL arguably replaced Latour's intermediary (didactic pedagogy). PBL's success in this area was more impressive due to the prevailing acceptance of didactic approaches in the school system by students who carried this culture with them to university (as mentioned above (BU lecturer 1). Evidence of this change was also manifest within the use of space in the courses. As Monihan (2002: 5) notes, '[a] classroom with neat rows of desks embodies pedagogies or "tacit curricula" of discipline and conformity, whereas spaces personifying flexible properties ... can be said to embody pedagogies of freedom and self-discovery'.

A key aspect of the PBL technique is its ability to be fluid and flexible in outcome (Laet and Mol 2000). PBL in the METHODS project had a variety of outcomes across several subject disciplines; it offered just enough rules for teachers to feel in control and for students to feel engaged as they investigated and explored their own projects. It is this shifting of teacher and student control and agency that makes PBL 'sticky' Gladwell (2015), easy to understand, not overly risky for teachers, and not totally free for students. PBL's fluidity may be the element that ensures that the Actor Network becomes stable. All lecturers interviewed felt they could continue and spread the method to other courses, and some had already done so. Yet they also said it was hard work and could not be done with large groups. This will probably be the next challenge to face - how does PBL become scaled and more importantly, does it need to be scaled? In spite of its worth and its impact on students and lecturers, PBL probably needs an Actor Network with a defined goal. Without the network in place, PBL may not be sustained in the long run.

\section{Conclusions}


PBL with its supporting network of lecturers, students, intellectual technology, the METHODS project itself, a training programme and the recruitment of the administration of each university was part of a situated Actor Network. Using ANT retrospectively to analyse research that has been undertaken gives a fresh perspective on the elements within a system and how they might affect change. Key in this is the conceptual realisation that the network bounds the activity - there are only the actors, human and non-human. ANT ideally does not connect things that already exist but actually configures networks (Fenwick 2010), and this was the case with the METHODS project.

A further analytical tool that ANT supplies is the black box concept which allowed the box of teaching and learning to be opened and the actors within to be examined. This, in turn, allowed examination of the mechanism of self-organisation which allows agency to be released. That each Actor Network can become a node (Callon 1991) in a wider network is also interesting when looking at further connections. Equally, each actor/actant is in itself a black box or ontological network. This conceptual realisation gives an insight into why PBL was so resonant with Palestinian lecturers and students - each of them has the occupation and their response to it in their personal ontologies, lived experiences and narratives. A question remains of how long PBL will be sustained within this Actor Network and how long the other actors that have supported the change will continue to do so. Fenwick and Edwards (2012: 5) note that the more allies a network has, the more actors are recruited, the more stable the network becomes. Whether this is the case in this network would require further enquiry to establish. From the research undertaken there were signs of support through a genuine desire to engage students who were particularly demotivated. Lecturers were mostly pleased by the increased levels of engagement and there was a conscious need to develop critical thinking and collaborative skills within learners.

In future interventions, ANT could also be used upfront as an instrument of design for educational change. (Law 1988: 61) suggests that we should act as socio-technical engineers 'creating something that is new by selecting and reshaping existing materials'. Within speculative design, research probes are used to create responses to actant switching. Foley and Lockton (2018) call this creating 'service fictions' where participants are asked to co-create the range of responses they might have to a speculative counterfactual change in their own context. This is clearly something that could be used in the creation of learning designs. Rather than just switching something into the network it would be advantageous to use the speculative design framework to project what might occur within a network.

ANT also uses the 'triangle of self-organisation' at the scale of its network in that it has rules of assemblage, a goal or purpose, and usually an imperative. That each node of the network is also an actant/actor implies that these may also invoke more or less agency in others depending on their inherent disposition, mechanisms and purposes. Larger constructs can be included in ANT (like 'the occupation' in Palestine) but only if they are directly involved or instigators of a change. ANT involves an understanding of granularity in the way it recruits other networks to an assemblage, but it does so by motivation towards a purpose or goal. The actors define the system boundaries, but ANT advocates must also always be on their guard against their own presence in the account and their bias (McLean and Hassard 2004). Ideally, those actants that are combined together to act towards a particular issue, even though they might have differing reasons for doing so, are the network and their motivations for taking part need to be explored and verified for both inclusion and exclusion. ANT is consequently suitable for looking retrospectively at interventions that sought to address an issue and is equally useful for designing and engineering new socio-technical networks towards a defined goal or purpose. It is perhaps this second interpretation that is most important for education - how to engineer both new and existing networks for transformation and change - with one's 'skin in the game' declared at the outset.

\section{References}

Arthur, W.B. (2009). The nature of technology: What it is and how it evolves. New York: Free Press.

Bandura, A. (1982). The assessment and predictive generality of self-percepts of efficacy. Journal of Behavior Therapy and Experimental Psychiatry, 13, 195-199. https://doi.org/10.1016/0005-7916(82)90004-0.

Bandura, A. (2001). Social cognitive theory: An agentic perspective. Annual Review of Psychology, 52(1), 1-26. http//doi.org/10.1146/annurev.psych.52.1.1.

Bandura, A. (2006). Toward a psychology of human agency. Perspectives on Psychological Science, 1(2), 164180. http//doi.org/ 10.1111/j.1745-6916.2006.00011.x.

Bernstein, B.B. (1977). Towards a theory of educational transmissions. London: Routledge and Kegan Paul.

Bossche, P.V.D., Gijselaers, W.H., Segers, M., \& Kirschner, P.A. (2006). Social and cognitive factors driving teamwork in collaborative learning environments. Small Group Research, 37(5), 490-521. http//doi.org/10.1177/1046496406292938.

Brandt, A. (2016). The triangle of self-organisation. https://www.infoq.com/articles/triangle-self-organization/. Accessed 3 April 2020.

Bueger, C., \& Stockbruegger, J. (2018). Actor Network Theory: objects and actants, networks and narratives. In McCarthy, D.R. (Eds,), Technology and World Politics: An Introduction. Abingdon: Routledge. 
Callon, M., \& Latour, B. (1981). Unscrewing the big leviathan: How actors macro-structure reality and how sociologists help them do so. In K. Knorr-Cetina \& A.V. Cicourel (Eds.), Advances in Social Theory and Methodology: Toward an Integration of Micro- and Macro-Sociologies (pp. 277-303). Boston: Routledge \& Kegan Paul.

Cause, L. (2010). Bernstein's code theory and the educational researcher. Asian Social Science, 6, 3. https://doi.org/10.5539/ass.v6n5p3.

Cauce, A.M., \& Gordon, E.W. (2013). Toward the measurement of human agency and the disposition to express it. Princeton, NJ: The Gordon Commission on the Future of Assessment in Education. https://www.ets.org/Media/Research/pdf/cauce_gordon_measurement_human_agency.pdf. Accessed 20 November 2019.

Cressman, D. (2009). A brief overview of Actor Network Theory: punctualization, heterogeneous engineering \& translation. Vancouver: Centre for Policy Research on Science and Technology, Simon Fraser University. http://citeseerx.ist.psu.edu/viewdoc/download?doi=10.1.1.869.2972\&rep=rep1\&type=pdf. Accessed 14 November 2019.

Dunne, A., \& Raby, F. (2013). Speculative everything: design, fiction, and social dreaming. Cambridge, MA: MIT Press.

Fenwick, T. (2010). (un)Doing standards in education with actor-network theory. Journal of Education Policy, 25(2), 117-133. http//doi.org/10.1080/02680930903314277.

Fenwick, T. \& Edwards, R. (Eds). (2012). Researching education through actor-network theory. Hoboken: John Wiley \& Sons.

Foley, S.M., \& Lockton, D. (2018). Service fictions through actant switching. In C. Storni, K. Leahy, M. McMahon, P. Lloyd, \& E. Bohemia (Eds.), Proceedings of DRS 2018: Design as a catalyst for change (pp. 201-218). London: Design Research Society. http//doi.org/10.21606/drs.2018.486.

Gee, J.P. (2005). What would a state of the art instructional video game look like? Innovate, 1(6). http://www.innovateonline.info/index.php?view=article\&id=80. Accessed 20 November 2019.

Gibson, J.J. (1977). The theory of affordances. In R.E. Shaw \& J. Bransford (Eds.), Perceiving, Acting, and Knowing. Hillsdale, NJ: Lawrence Erlbaum Associates.

Gibson, F. (1977). Bernstein's classification \& framing: a critique. Higher Educational Review, 9, $23-45$.

Gladwell, M. (2015). The tipping point: How little things can make a big difference. London:Abacus.

Graff, E., \& Kolmos, A. (2003). Characteristics of problem-based learning. International Journal of Engineering, 19(5), 657-662.

King, R. (1981). Bernstein's sociology of the school. British Journal of Sociology, 32, 259-265.

Laet, M.D., \& Mol, A. (2000). The Zimbabwe bush pump. Social Studies of Science, 30(2), $225-263$. http//doi.org/10.1177/030631200030002002.

Latour, B. (1987). Science in action: how to follow scientists and engineers through society. Cambridge, MA: Harvard University Press.

Latour, B. (2008). Reassembling the social: an introduction to Actor Network-theory. Oxford: Oxford University Press.

Latour, B. (1996). On Actor Network Theory. A few clarifications plus more than a few complications. Soziale Welt, 47, 369-381.

Law, J. (1994). Organizing Modernity. Oxford: Blackwell Publishers.

Law, J. (2003). Making a mess with method. Lancaster: University of Lancaster. https://www.lancaster.ac.uk/fass/resources/sociology-online-papers/papers/law-making-a-mess-withmethod.pdf. Accessed 09 April 2020.

Law, J. (1988). Six Principles for the Interdisciplinary Analysis of Technology. In E. Mayer (Ed.), Ordnung Rationalisierung, Kontrolle (pp. 55-77). Darmstadt: Technischen Hochschule

Magnussen, R. (2016). Training slides: methods project training. Wolverhampton: University of Wolverhampton. (Unpublished PowerPoint slides).

Monahan, T. (2002). Flexible space \& built pedagogy: Emerging IT embodiments. Inventio, 4(1): 1-19. Norman, D. A. (1988). The psychology of everyday things. New York: Basic Books.

Norman, D.A. (2004). Affordances and design. https://www.researchgate.net/publication/265618710_Affordances_and_Design. Accessed 30 November 2019.

Nussbaum, M.C. (2011). Creating capabilities: The human development approach. Cambridge, MA: Belknap Press.

Oosterlaken, I. (2015). Technology and human development. Oxford, UK: Routledge.

Pendleton-Jullian, A.M., \& Brown, J.S. (2018). Design unbound vol. 2. Ecologies of change for a white water world. Cambridge, MA: The MIT Press.

Pólya, G. (1957). How to solve it: A new aspect of mathematical method. Garden City, NY: Doubleday \& Company. 
Robeyns, I. (2005). Assessing global poverty and inequality: income, resources, and capabilities. Metaphilosophy, 36(1-2), 30-49. http//doi.org/10.1111/j.1467-9973.2005.00355.x.

Royle, K. \& Nikolic, J. (2016). A modern mixture, agency, capability, technology and 'scrum': agile work practices for learning and teaching in schools. Journal of Education \& Social Policy, 3(3),37-47.

Royle, K. \& Scott, D.S. (2018). Methods project final evaluation report. Internal methods project report. Wolverhampton: University of Wolverhampton.

Royle, K. (2019). Opening spaces for the development of human agency with problem based learning in Palestinian higher education. In L. Uden, D. Liberona, G. Sanchez, \& S. Rodríguez-González (Eds.), Learning Technology for Education Challenges (pp. 260-278). Cham: Springer. https://doi.org/10.1007/978-3-030-20798-4_23.

Ryberg, T., Koottatep, S., Pengchai, P., \& Dirckinck-Holmfeld, L. (2006). Conditions for productive learning in networked learning environments: A case study from the VO@NET project. Studies in Continuing Education, 28(2), 151-170. https://doi.org/10.1080/01580370600751138.

Savin-Baden, M. (2014). Using problem-based learning: New constellations for the 21st century. Journal on Excellence in College Teaching, 25(3-4), 197-219.

Sen, A. (1985). Well-being, agency, and freedom. The Dewey Lectures 1984. The Journal of Philosophy, 82, 169221.

Sen, A. (1992). Inequality re-examined. Oxford, UK: Oxford University Press.

Tobias, S. (2005). Foucault on freedom and capabilities. Theory, Culture \& Society, 22(4), 65-85. http//doi.org/10.1177/0263276405053721.

Yahya, A.H. (2018). Tools for internationalizing higher education in developing countries. In H.M. Fardoun, K.J. Downing, \& M. Mok (Eds.), The Future of Higher Education in the Middle East and Africa (pp. 87103). Cham: Springer. https://doi.org/10.1007/978-3-319-64656-5 9.

Yaneva, A. (2009). Making the social hold: towards an Actor Network Theory of design. Design and Culture, 1(3), 273-288. https://doi.org/10.1080/17547075.2009.11643291.

Yates, F. (1983). What Is Self-Organization? Princeton, NJ: Princeton University Press. 